\title{
Compressibility of Eleven Inorganic Materials
}

\author{
C. E. Weir
}

(September 2, 1964)

\begin{abstract}
Volume compression measurements were made on eleven inorganic materials to a maximum pressure of $10,000 \mathrm{~atm}$. Coefficients of the empirical equation $-\Delta V / V_{\mathrm{o}}=a(P$ $-2000)+b(P-2000)^{2}$ were determined for the substances studied. Values of $a$ in units of $10^{-6} \mathrm{~atm}^{-1}$ and $b$ in units $10^{-10} \mathrm{~atm}^{-2}$ are as follows: Monel- $a=0.62 b=0$; Waspalloy- $a$ $=0.65, b=0$; sapphire $a=0.34, b=0$; rutile $a=0.46, b=0 ;$ spinel $-a=0.39, b=0 ; \mathrm{BaS}-a$ $=3.99, b=-1.6 ; \mathrm{CaS}-a=2.48, b=-1.1 ; \mathrm{B}_{2} \mathrm{O}_{3}$ (crystalline) $-a=3.24, b=-0.29 ; \mathrm{H}_{3} \mathrm{BO}_{3}$ $a=11.65, b=-3.2 ; \mathrm{As}_{2} \mathrm{O}_{3}$ (glass) $-a=8.34, b=-1.7 ;$ and $\mathrm{As}_{2} \mathrm{~s}_{3}$ (glass) $-a=8.12, b=-2.8$.
\end{abstract}

\section{Introduction}

During several years of systematic studies of P-V behavior of solids, data were occasionally obtained on a few miscellaneous materials. These materials were studied because of requests for the data or as part of a proposed systematic study which never materialized. Inasmuch as the $\mathrm{P}-\mathrm{V}$ data (and the derived compressibilities) were of sufficient interest to warrant investigation, they appear to deserve publication. This report contains volume compression data on 11 inorganic materials studied at room temperature to a maximum pressure of $10,000 \mathrm{~atm}$.

\section{Experimental Method and Materials}

The method used has been described previously in considerable detail [1] ${ }^{1}$ and will be outlined here briefly. The specimen was immersed in Varsol in the bore of a heavy-walled steel vessel. A leakproof piston forced into the bore generated pressure in the Varsol, thereby compressing both the Varsol and the specimen. A similar experiment was performed in which a steel bar of similar volume replaced the specimen. Comparison of the piston position at equal pressures in the two experiments permitted calculation of the compression $\left(-\Delta V / V_{\mathrm{o}}\right)$ of the unknown in terms of the compression of steel which is known [2]. ${ }^{2}$ Pressure was measured by means of \footnotetext{
1 Figures in brackets indicate the literature references at the end of this paper.
2 The question of the variability of compressibility of steel with composition 2 The question of the variability of eompressibility of steel with composition
was investigated by L. H. Adams. He did not publish the results but found that Wasinvestigated by L. H. Adams. He did not publish the results but found that Bridgman's compressibility value for steel was valid for straight carbon steels
within the experimental error of the measurement of the compressibility. The within the experimental error of the measurement of the compressibility. The
reference steel bars used here were fabricated from drill rod, which contains approximately 0.9 percent carbon.
}

a manganin coil immersed in the Varsol inside the pressure vessel. The pressure gage was calibrated at the water-ice VI transition point at room temperature [3]. In such experiments a fiducial point at 2,000 atm was used because of friction in the packing washers of the movable piston. All volume changes were calculated from this pressure.

The materials studied and their method of preparation were as follows:

1. Monel metal ${ }^{3}$ - this Nickel-copper alloy was obtained commercially.

2. Waspalloy - a complex alloy of nickel was also obtained commercially. Both of these alloys were studied in the annealed state in the form of bars approx. $1 / 2$ in. diam. $\times 4$ in. long.

3. Sapphire - several rods of $\mathrm{Al}_{2} \mathrm{O}_{3}$, each a single crystal, prepared by the flame-fusion process comprised the specimen studied. The specimens were obtained commercially.

4. Rutile - a single crystal rod of $\mathrm{TiO}_{2}$ approx. $1 / 2$ in. diam. $\times 4$ in. long was prepared by flame fusion. The specimen was heated in an oxygen atmosphere subsequent to formation but was still oxygen deficient as indicated by its purplish color.

5. Spinel-hand-picked natural spinel crystals obtained from Ceylon gravel. The specimen studied was composed of a quantity of small crystals contained in an open steel cylinder.

6. $\mathrm{B}_{2} \mathrm{O}_{3}$ - crystalline $\mathrm{B}_{2} \mathrm{O}_{3}$ was obtained from dehydrated $\mathrm{H}_{3} \mathrm{BO}_{3}$ by the method described by Kracek et al. [4]. The specimen consisted of \footnotetext{
${ }^{3}$ Both Monel and Waspalloy are nickel alloys with the following nominal
compositions (values reported are percentages, given only for those components compositions (values repor present in excess of $1 \%$

Monel; Ni-67, Cu-30, Fe-1.5, Mn-1.0, Si, C

Waspalloy; Ni-59, Cr-19.5, Co-13.5, Mo-4.3, Ti-3.0, Al-1.4, Fe, B, Zr.
} 
several large fragments contained in an open steel cylinder. Although the specimen was crystalline it was not certain that it did not also contain a small quantity of uncrystallized $\mathrm{B}_{2} \mathrm{O}_{3}$ glass.

7. $\mathrm{H}_{3} \mathrm{BO}_{3}-$ orthoboric acid was a reagent grade material. The specimen consisted of polycrystalline powder contained in an open steel cylinder.

8. $\mathrm{As}_{2} \mathrm{O}_{3}$ - glass, prepared by melting reagent grade material in a sealed, evacuated tube. The specimen consisted of a cylindrical bar.

9. $\mathrm{As}_{2} \mathrm{~S}_{3}$ glass, preparation and specimen similar to $\mathrm{As}_{2} \mathrm{O}_{3}$.

10. CaS-powdered material of commercial origin. The specimen was contained in a steel cylinder.

11. BaS - also commercially prepared powder. Handled as in the case of CaS.

\section{Results and Discussion}

The experimental compression data are divided into two groups based on the magnitude of the compression. The data are given in tables 1 and 2 . In table 1 data are given for the compression of the less compressible materials while those for the more compressible materials are given in table 2 .

For each material of low compressibility at least two independent measurements were made on each specimen and the averages are given in table 1 . In general, the duplicate measurements showed that variations occurred in the fourth significant figure. Measurements made to five significant figures have been rounded off in the data of table 1 to four figures. For substances of medium compressibility duplicate measurements were made on only $\mathrm{BaS}$ and $\mathrm{CaS}$, all other data represent the results of one determination. Several measurements were made on fresh specimens of both $\mathrm{BaS}$ and $\mathrm{CaS}$ from the same samples with some evidence that decomposition of the samples occurred with time. This result was inferred from a small but significant increase in compression with age of sample. The data reported for these two sulfides represent the averages of data obtained in the first two measurements on each compound.

TABLE 1. Compression data for inorganic solids of low compressibility

Compression, $-\Delta \mathrm{V} / \mathrm{V}_{0}$

\begin{tabular}{|c|c|c|c|c|c|}
\hline Pressure, atm & Monel & Waspalloy & Sapphire & Rutile & Spinel \\
\hline 10000 & 0.0048 & 0.0050 & 0.0026 & 0.0035 & 0.0032 \\
\hline 9000 & & & $\begin{array}{l}0.0020 \\
24\end{array}$ & $\begin{array}{r}0.0000 \\
32\end{array}$ & $\begin{array}{l}0.0022 \\
29\end{array}$ \\
\hline 8000 & $\begin{array}{l}71 \\
38\end{array}$ & 40 & 21 & $\begin{array}{l}32 \\
25\end{array}$ & 23 \\
\hline 7000 & $\begin{array}{l}30 \\
31\end{array}$ & 33 & 19 & 23 & 18 \\
\hline 6000 & & 28 & 16 & $\begin{array}{l}20 \\
19\end{array}$ & 13 \\
\hline 5000 & 19 & 21 & 10 & $\begin{array}{l}19 \\
15\end{array}$ & 10 \\
\hline 4000 & 12 & 14 & 5 & 10 & 8 \\
\hline 3000 & & & 4 & & 5 \\
\hline 2000 & 0.0000 & 0.0000 & 0.0000 & $0.0000^{ \pm}$ & 0.0000 \\
\hline
\end{tabular}

For each set of data of tables 1 and 2 an empirical equation of the form

$-\Delta V / V_{0}=a(P-2000)+b(P-2000)^{2}$ was fitted and the coefficients determined by the method of least squares. For the data of table 1 it is unlikely that values of the coefficient $b$ would be meaningful because of the low compressibility.

TABLE 2. Compression data for inorganic solids of medium compressibility

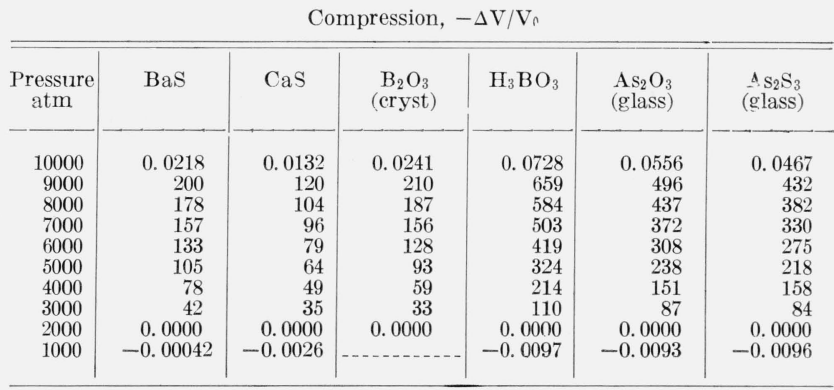

For these materials the linear form was assumed and only a single coefficient was derived. For the substances of table 2 , the pressure-compression relation is distinctly nonlinear and a nonzero value of $b$ is required. The appropriate values of $a$ and $b$ are given in table 3 .

TABLE 3. Value of coefficients a and $\mathrm{b}$ of the equation $-\Delta \mathrm{V} / \mathrm{V}_{0}=\mathrm{a}(\mathrm{P}-2000)+\mathrm{b}(\mathrm{P}-2000)^{2}$

\begin{tabular}{|c|c|c|}
\hline Material & $a, 10^{-6} \mathrm{~atm}^{-1}$ & $-b, 10^{-10} \mathrm{~atm}^{-2}$ \\
\hline Monel_.... & 0.62 & \\
\hline Waspalloy & .65 & \\
\hline Sapphire $\left(\mathrm{Al}_{2} \mathrm{O}_{3}\right) \ldots$ & .34 & \\
\hline Rutile $\left(\mathrm{TiO}_{2}\right)$ & .46 & ..... \\
\hline $\begin{array}{l}\text { Spinel }\left(\mathrm{MgAl}_{2} \mathrm{O}_{4}\right) \\
\mathrm{BaS}\end{array}$ & $\begin{array}{r}.39 \\
3.99\end{array}$ & \\
\hline $\begin{array}{l}\text { BaS } \\
\text { CaS }\end{array}$ & $\begin{array}{l}3.99 \\
2.48\end{array}$ & $\begin{array}{l}1.6 \\
1.1\end{array}$ \\
\hline $\mathrm{B}_{2} \mathrm{O}_{3}$ (cryst) & 3. 24 & 0.29 \\
\hline $\mathrm{H}_{3} \mathrm{BO}_{3} \ldots$ & 11.65 & 3.2 \\
\hline $\mathrm{As}_{2} \mathrm{O}_{3} \ldots$ & 8. 34 & 1.7 \\
\hline $\mathrm{As}_{2} \mathrm{~S}_{3--}$ & 8.12 & 2.8 \\
\hline
\end{tabular}

The data given in tables 1,2 , and 3 require little discussion. The data for Monel and Waspalloy appear to be in reasonable agreement with the values expected from simple mixtures of their respective components. Volume compression data on sapphire and rutile were obtained to provide a check on the data of Bridgman who measured only linear compression $[5,6,7]$. The agreement between volume compressions calculated from Bridgman's linear compression data and the experimental values reported here is very good. In fact, the agreement is much better than might be expected considering the experimental difficulties in measuring volume compressions of such incompressible materials. So far as can be ascertained there are no previous compression data on spinel. Data on BaS and CaS were obtained because it was suspected that Bridgman's results might be too large $[8,9]$. However, the compressions obtained here are fully as large and in addition do not agree with Bridgman's results particularly well. From observations made here, it would appear that the question of purity may be of importance in producing the somewhat discordant 
data obtained on these two sulfides. The compressibility of crystalline $\mathrm{B}_{2} \mathrm{O}_{3}$ is considerably less than that obtained previously on the glass [10], as is to be expected. It is to be noted that the value of $b$ for $\mathrm{B}_{2} \mathrm{O}_{3}$ is much lower than the corresponding values found for $\mathrm{BaS}$ and $\mathrm{CaS}$, even though the values of $a$ are comparable in these three compounds. Inasmuch as $b$ represents the pressure coefficient of compressibility which is large for $\mathrm{B}_{2} \mathrm{O}_{3}$ glass [10] it may be concluded that the quantity of glass in the specimen of crystalline $\mathrm{B}_{2} \mathrm{O}_{3}$ is small and that the numerical data are representative of the crystals. The compression data on $\mathrm{H}_{3} \mathrm{BO}_{3}$ was measured routinely as were the two arsenic glasses. These results require no comment.

The author is indebted to A. Friedman for the specimens of Monel and Waspalloy, to J. Wachtman for the sapphire and rutile, and to $\mathrm{H}$. Yoder for the spinel. R. Waxler assisted in a few of the measure-

\section{References}

[1] C. E. Weir, J. Res. NBS 45, 468 (1950) RP2160.

[2] P. W. Bridgman, The physies of high pressure, p. 417 (G. Bell \& Sons Ltd., London, 1949).

[3] P. W. Bridgman, Proc. Am. Acad. Arts \& Sci. 47, 441 (1911).

[4] F. C. Kracek, G. W. Morey, and H. E. Merwin, Am. J. Sci., 35A, 143 (1938).

[5] P. W. Bridgman, Proc. Am. Acad. Arts \& Sci. 68, 27 (1933).

[6] P. W. Bridgman, Am. J. Sci. 10, 483 (1925).

[7] P. W. Bridgman, Am. J. Sci. 15, 1 (1928).

[8] P. W. Bridgman, Proc. Am. Acad. Arts \& Sci. 74, 21 (1940).

[9] M. L. Huggins and Y. Sakamoto, J. Phys. Soc. Japan 12, 241 (1957).

[10] C. E. Weir and L. Shartsis, J. Am. Ceram. Soc. 38, 299 (1955). ments. 